\title{
LETTERS
}

\section{The authors respond to: "Revamp governance of Canadian Task Force on Preventive Health Care"}

The Canadian Task Force on Preventive Health Care is an independent body that develops evidence-based guidelines to support primary care providers to deliver the best possible preventive health care to Canadians. It comprises experts in primary care, public health, preventive medicine and guideline methodology. The task force represents the people of Canada, not other organizations such as industry or special interest groups, to avoid inherent biases and conflicts of interest. ${ }^{1,2}$ The task force places a high level of emphasis on its rigorous approach to the identification of relevant evidence and the synthesis of evidence: it utilizes the Grading of Recommendations Assessment, Development and Evaluation (GRADE) methodology to inform its evidence-based guidelines and to communicate its decisions in a transparent manner. ${ }^{3-6}$

Unlike scenarios where patients seek medical care because they are experiencing symptoms, screening invites otherwise healthy people to undergo testing and, when abnormalities are found, subsequent intervention. Screening has both potential harms and benefits, and it is critical that patients and care providers have a thorough understanding of these harms and benefits before making decisions about undergoing any screening procedure. It would be irresponsible to recommend that Canadians participate in widespread screening practices in the absence of reasonable confidence of net benefit.

In his letter to CMAJ, Dr. Yaffe ${ }^{7}$ asserted that the evidence of benefit for breast cancer screening is clear and unequivocal. He argued that high-quality data from randomized controlled trials (RCTs) for "newer" breast cancer-screening technologies is absent and that the task force should simply lower the evidentiary bar, rely upon poorer-quality evidence (including observational studies) and recommend that all women undergo screening. We disagree for several reasons.
First, the benefit of newer approaches over traditional mammography is unconfirmed; newer screening technology may not always mean "better." Newer technology screening tests may be more sensitive, but this can lead to more false positives and increased rates of overdiagnosis. Overdiagnosis occurs when cancers that would never have caused harm over a woman's lifetime are identified through screening, exposing women to surgery and chemotherapy for cancers that would never have been clinically apparent if screening were not performed. Overdiagnosis is widely recognized as a substantial harm of screening. ${ }^{8}$ Reliable evidence of possible harms and benefits of newer technologies is not available; however, this is critical information that is needed to inform rational recommendations.

Second, we agree with Dr. Yaffe that "cherry picking" evidence introduces bias and should be avoided. As an example, Dr. Yaffe cited a single retrospective cohort study as evidence that screening reduces surgery and chemotherapy; ${ }^{9} \mathrm{a}$ Cochrane systematic review of randomized trials, however, reported the opposite conclusion. ${ }^{10}$ It is critical that clinical guidance is based on systematic review of evidence that uses accepted methods to minimize bias and considers the totality of evidence, ${ }^{11}$ which the task force did in developing its recommendations on breast cancer screening. ${ }^{12}$

Third, Dr. Yaffe suggested that observational data on breast cancer screening make a clear and strong case that benefits outweigh the harms. In 2016, the United States Preventive Services Task Force did a systematic review of the types of observational studies on breast cancer screening that Dr. Yaffe used to provide evidence that supported his position. The US task force concluded that this type of evidence had "mixed results" and had substantial biases that limited their use in determining effectiveness, and it was ultimately deemed insufficient to assess additional benefits and harms. ${ }^{13}$ Dr. Yaffe cited a review by the International Agency for Research on Cancer as evidence of a consensus of the clear net benefit of breast cancer screening. However, consistent with the task force recommendation, ${ }^{12}$ the authors of that review concluded that the evidence on breast cancer screening for women aged 40-49 years was too limited to support a recommendation for screening in this age group. ${ }^{14}$ Showing equipoise for this issue, a large cluster RCT of breast cancer screening in women younger than 50 years is currently underway in the United Kingdom to determine if there is benefit from screening in these women (clinicaltrials.gov, NCT01081288).

The task force recommendations on breast cancer screening are concordant with those of other reputable guideline producers that use evidence-based approaches, including major national guidelines in the US, UK and Australia. ${ }^{13,15,16}$ Consistent with the Canadian task force guideline, these international guidelines do not recommend unproven screening technologies (e.g., digital tomosynthesis and magnetic resonance imaging) or supplemental screening in women with increased breast density after a negative result for a mammogram because there is insufficient evidence to assess harms and benefits of clinically meaningful outcomes. A recent appraisal of major international guidelines for breast cancer screening by the American College of Physicians assigned the Canadian task force guideline the highest score for overall quality rating: more reviewers recommended the task force guideline for use than any other guideline. ${ }^{17}$

The task force used a rigorous, unbiased, evidence-based review and approach to develop its guideline on breast cancer screening to provide women and their primary care providers with the best evidence to make informed decisions. ${ }^{12}$ Lowering our rigorous standards would be a disservice to both primary care providers and women affected by screening recommendations. We are confident that our recommendations are sound and consider not only the best available evidence, but also provide Canadian women aged 40-74 years with the information they 
need to make an informed choice based on their values and preferences through shared decision-making in partnership with their physicians.

\section{Scott W. Klarenbach MD MSc}

Nephrologist and professor, Department of Medicine, University of Alberta,

Edmonton, Alta.

\section{Ainsley E. Moore MD MSc}

Associate clinical professor, Department of Family Medicine, McMaster University, Hamilton, Ont.;

\section{Brett D. Thombs PhD}

Senior investigator, Lady Davis Institute of the Jewish General Hospital; professor, Departments of Psychiatry; Epidemiology, Biostatistics, and Occupational Health; Medicine; Psychology; and Educational and Counselling Psychology, McGill University, Montréal, Que.

\section{For the Canadian Task Force on Preventive Health Care*}

Cite as: CMAJ 2020 February 10;192: E146-7. doi: 10.1503/cmaj.74313

\section{References}

1. Jatoi I, Sah S. Clinical practice guidelines and the overuse of health care services: need for reform. CMAJ 2019;191:E297-8.

2. Kelsall D. New CMAJ policy on competing interests in guidelines. CMAJ 2019;191:E350-1.

3. Schünemann $\mathrm{H}$, Brożek J, Guyatt $\mathrm{G}$, et al. GRADE handbook: handbook for grading the quality of evidence and strength of recommendations using the GRADE approach. GRADE Working Group; 2013. Available: http://gdt.guidelinedevelopment .org/app/handbook/handbook.html (accessed 2019 May 21).
4. Canadian Task Force on Preventive Health Care procedure manual. Canadian Task Force on Preventive Health Care; 2014. Available: https:// canadiantaskforce.ca/methods/ (accessed 2019 May 21).

5. Barbeau P, Stevens A, Beck A, et al. Breast cancer screening: Part A. An evidence report to inform an update of the Canadian Task Force on Preventive Health Care 2011 guideline (Prepared by the Knowledge Synthesis Group, Ottawa Methods Centre, Ottawa Hospital Research Institute for the Canadian Task Force on Preventive Health Care under contract by the Public Health Agency of Canada). Canadian Task Force on Preventive Health Care; 2017. Available: https://canadiantaskforce.ca/wp-content/ uploads/2019/02/Systematic-Review-Evidence -Report_V2_FINAL.pdf (accessed 2019 May 21).

6. Pillay J, MacGregor T, Hartling L, et al. Breast Cancer Screening: Part B. Systematic review on women's values and preferences to inform an update of the Canadian Task Force on Preventive Health Care 2011 guideline. (Prepared by the Alberta Evidence Review and Synthesis Centre for the Canadian Task Force on Preventive Health Care under contract by the Public Health Agency of Canada). Canadian Task Force on Preventive Health Care; 2017. Available: https://canadiantaskforce.ca/ wp-content/uploads/2018/11/Womens-Values-and -Preferences-on-Breast-Cancer-Screening_FINAL. pdf (accessed 2019 May 21).

7. Yaffe MJ. Revamp governance of Canadian Task Force on Preventive Health Care [letter]. CMAJ 2020;192:E145.

8. Marcus PM, Prorok PC, Miller AB, et al. Conceptualizing overdiagnosis in cancer screening. J Natl Cancer Inst 2015;107:djv014.

9. Barth RJ, Gibson GR, Carney PA, et al. Detection of breast cancer on screening mammography allows patients to be treated with less-toxic therapy. AJR Am J Roentgenol 2005;184:324-9.

10. Gøtzsche PC, Jørgensen K. Screening for breast cancer with mammography. Cochrane Database Syst Rev 2013;(6):CD001877.

11. Guyatt $G H$, Oxman AD, Vist $G$, et al. GRADE guidelines: 4. Rating the quality of evidence-study limitations (risk of bias). J Clin Epidemiol 2011;64:407-15.

12. Klarenbach S, Sims-Jones N, Lewin G, et al. Recommendations on screening for breast cancer in women aged 40-74 years who are not at increased risk for breast cancer. CMAJ 2018;190: E1441-51.

13. Siu AL; U.S. Preventive Services Task Force. Screening for breast cancer: U.S. Preventive Services Task Force recommendation statement. Ann Intern Med 2016;164:279-96.

14. Fitzgerald SP. Breast-cancer screening - viewpoint of the IARC Working Group. N Engl J Med 2015;373:1479.

15. Breast screening: programme overview [guidance]. London (UK): Public Health England; 2015. Available: www.gov.uk/guidance/breast -screening-programme-overview (accessed 2019 May 21).

16. Early detection of breast cancer. Surry Hills (AU): Cancer Australia; 2004 (updated 2009, revised 2015). Available: https://canceraustralia.gov.au/ publications-and-resources/position-statements /early-detection-breast-cancer (accessed 2019 May 21).

17. Qaseem A, Lin JS, Mustafa RA, et al. Screening for breast cancer in average-risk women: a guidance statement from the American College of Physicians. Ann Intern Med 2019;170:547-60.

*Collaborating members of the Canadian Task Force on Preventive Health Care: Ahmed Abou-Setta, Heather Colquhoun, Roland Grad, Stéphane Groulx, Michael Kidd, Tina Korownyk, Eddy Lang, John LeBlanc, Navindra Persaud, Donna Reynolds, John Riva, Guylène Thériault and Brenda Wilson. The complete list of all current members of the Canadian Task Force on Preventive Health Care is available at http:// canadiantaskforce.ca/about/members.

Funding: Funding for the Canadian Task Force on Preventive Health Care is provided by the Public Health Agency of Canada. The views of the funding body have not influenced the content of the guideline. The views expressed in this article are those of the task force and do not necessarily represent those of the Public Health Agency of Canada.

Competing interests: None declared. 